\title{
Temporal change in reflected waves from deep crust possibly synchronized with the activity of DLFTs detected using ACROSS
}

\author{
Toshiki WATANABE ${ }^{1}$, Tomoyuki SOMA ${ }^{1}$ Ryoya IKUTA $^{2}$ and Koshun YAMAOKA ${ }^{2}$ \\ ${ }^{1}$ Graduate School of Environmental Studies, Nagoya University, Japan. \\ ${ }^{2}$ Earthquake Research Institute, University of Tokyo, Japan,
}

\begin{abstract}
ACROSS stands for Accurately Controlled, Routinely Operated Signal System. Repeated transmission of a controlled seismic signal and long-term continuous observation of the seismic waves enable precise monitoring of time-evolving physical properties of the Earth's interior. An observation using the ACROSS source was conducted in the Tokai distinct, Japan to establish a method to monitor the state of coupling of the plate boundary and to understand the time-evolving phenomena such as slow-slip and deep lowfrequency tremors (DLFTs). A seismic signal emitted from the ACROSS source was observed by a shortspan surface seismometer array and a Hi-net station (N.HOUH) located at the distance of $57 \mathrm{~km}$ from the source for 10 months. The transfer function clearly shows the P-wave, S-wave and their later-phases. Coherent later phases were detected using the semblance analysis of the array of transfer functions. They were interpreted as the reflections from the Moho and the plate boundary. The temporal changes of these phases were examined using Hi-net data which were free from environmental effects. The temporal changes of these phases show correlation with the episodic activity of the DLFTs in 2005. This implies the possibility of seismic monitoring of seismogenic plate-subduction zone using ACROSS.
\end{abstract}

\section{INTRODUCTION}

The Earth's interior evolves in time. Monitoring the Earth's activities including earthquakes and volcanic activities is a challenge in solid earth science and hazard mitigation. At the plate boundary, stress accumulation, aseismic slip, deep lowfrequency tremors (DLFTs) ${ }^{1)}$ and precursory slip may cause a variation in the physical properties. Seismic propagation characteristics are affected by the geomechanical, geochemical and hydrogeological contact conditions of the plate boundary. Seismic exploration and monitoring will provide important information to understand the mechanism of earthquake generation ${ }^{2,3)}$, the mechanism of the timeevolving phenomena and their relationship and interaction.

ACROSS (Accurately Controlled, Routinely Operated Signal System) is designed to monitor the time-evolving nature of the physical properties of the Earth's interior. Figure 1 illustrates the concept of monitoring the plate coupling and the associated activities using ACROSS signal reflected from the plate boundary.

ACROSS is based on the precisely repeated transmission of a controlled signal and long-term contin-

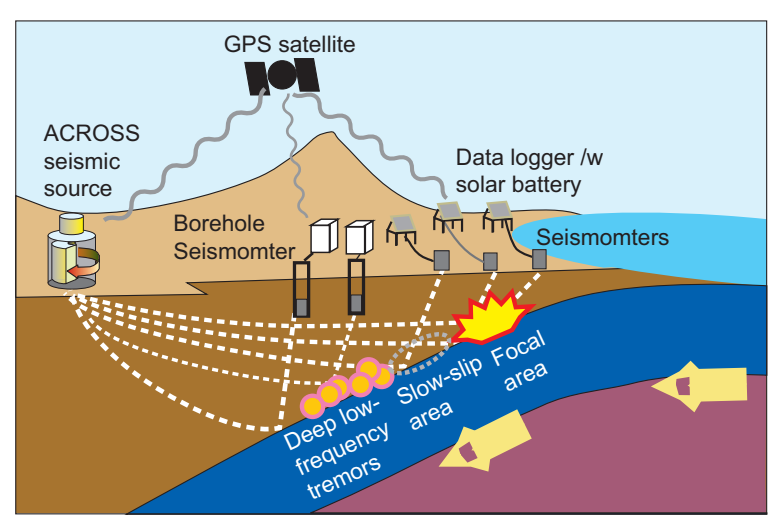

Figure 1. Concept of the Tokai active monitoring plan and the experiment using seismic ACROSS.

uous observation synchronized with GPS clock $^{4,5)}$. The source keeps generating the same frequencymodulated (FM) signal repeatedly for a long time? ${ }^{\text {? }}$. The observed signals are subdivided to segments of a certain time length and stacked in frequency domain to improve the $\mathrm{S} / \mathrm{N}$ ratio. Dividing the observed spectra by the source spectra yields the transfer function, representing the wave transmission from the source to the receiver. Inverse FFT can retrieve the time-domain representation of the transfer function that corresponds to the waveform obtained by 


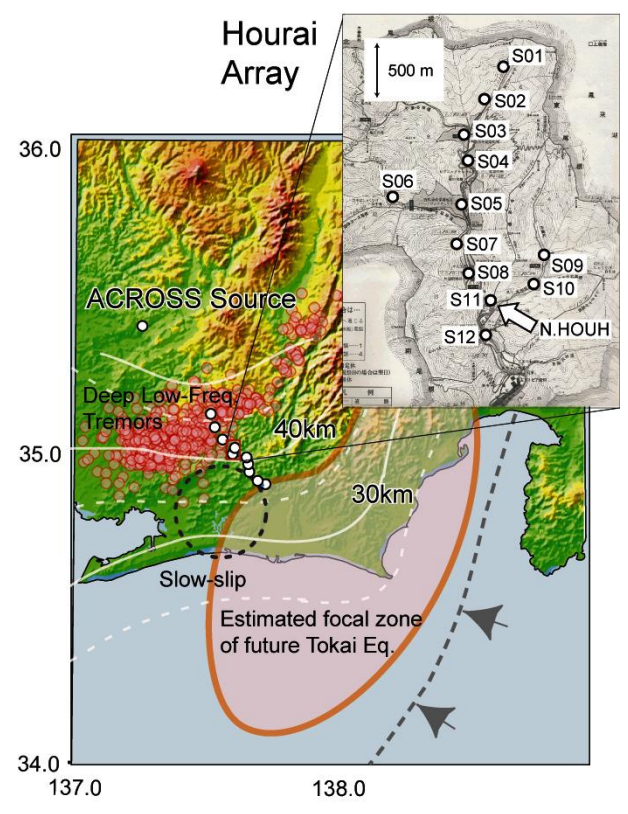

Figure 2. Locations of ACROSS source (in Toki city) and the line of seismic stations deployed for the experiment. An array of seismometers was deployed in Shinshiro City.

time-domain observations.

The ACROSS team in Nagoya University, together with University of Tokyo, Shizuoka University, and Tono Geoscience Center of Japan Atomic Energy Research and Development Agency (JAEA) is conducting a seismic monitoring in the crust and of the plate boundary in the Tokai district. This paper reports the temporal change in reflected waves from deep crust detected using ACROSS during a 10-months field observation. The temporal changes are possibly synchronized with the activity of DLFTs in the Tokai region in 2005.

\section{FIELD OBSERVATION}

Figure 2 shows the map of the study area, the locations of the ACROSS source and the survey line in the Tokai area ${ }^{7}$. The ACROSS source is located at JAEA Tono mine in Toki City, Gifu Prefecture. The seismic ACROSS source was operated to generate the frequency-modulated (FM) signal from 10 to $20 \mathrm{~Hz}$ for the period of 50 seconds during the observation. The rotation direction was reversed in every one hour to enable synthesizing linear motions in arbitrary directions.

A short-span surface seismometer array called "Hourai array" was deployed in Shinshiro City in eastern Aichi Prefecture shown in the blow-up in Figure 2. The array, composed of 12 stations, was about $2 \mathrm{~km}$ long in NS and $1 \mathrm{~km}$ wide in EW. Each station was equipped with three seismometers (Mark-

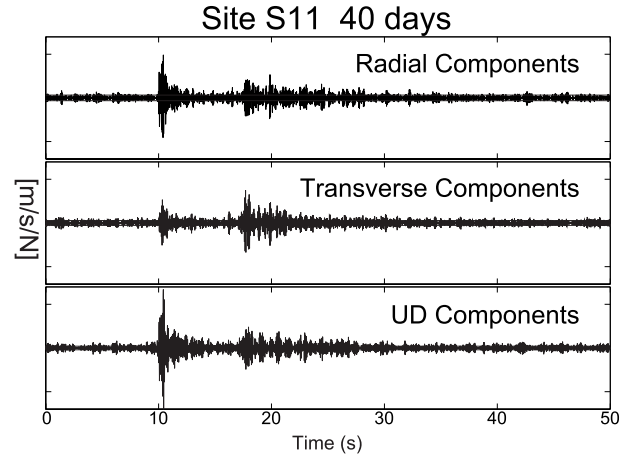

(a)

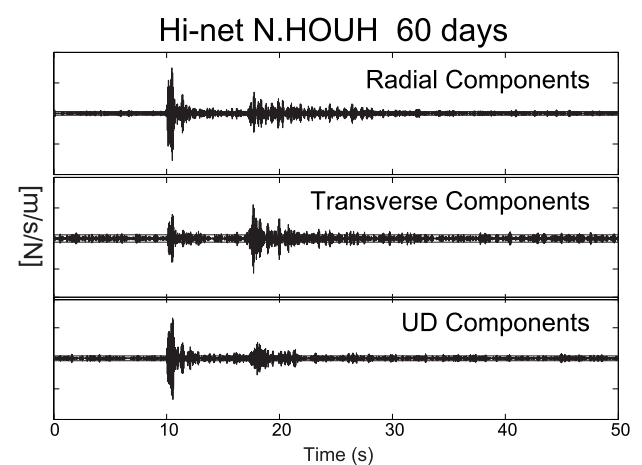

(b)

Figure 3. Time-domain transfer functions observed at the station S11 in the array and the Hi-net N.HOUH station.

Land L22D, $2 \mathrm{~Hz}$ ) in UD, NS and EW directions, a offline data logger (DataMark LS-7000) and an amplifier powered by a battery and a solar panel. The observation started in November, 2004 and continued until the end of September, 2005.

The continuous seismic data of Hi-net (a nationwide borehole high-sensitivity seismograph network operated by NIED) stations were also collected and processed. Our S11 station is located close to the Hinet station (N.HOUH).

\section{TRANSFER FUNCTIONS}

Figure 3 compares the transfer function obtained at the S11 station and the N.HOUH station. The horizontal lines indicate the noise level estimated theoretically from the ACROSS spectra. The transfer function obtained using the surface seismometer shows a good $\mathrm{S} / \mathrm{N}$ ratio and comparable to those for Hi-net station deployed in a borehole at a depth of $103 \mathrm{~m}$.

By comparing the $\mathrm{P}$ - and $\mathrm{S}$-wave arrivals estimated from the JMA standard traveltime table, the major arrivals were identified as $\mathrm{P}$ - and $\mathrm{S}$-waves arrivals. The waveforms including the later-phases show remarkably good coherency between the two stations. This ensures the quality of our data observed using the surface seismometers. 


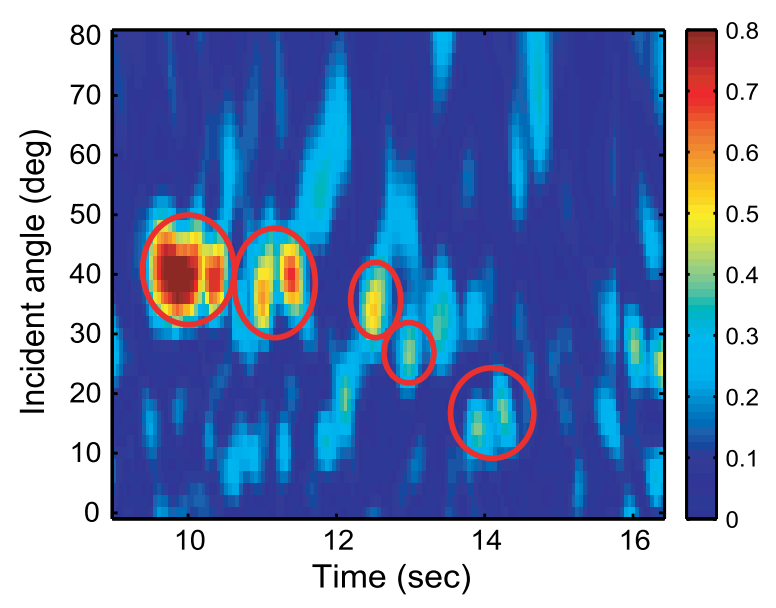

Figure 4. Semblance panel indicating the dependency of the semblance value of each phase in the transfer functions on the incident angle. The $\mathrm{P}$-wave velocity and the azimuth were fixed to 4 $\mathrm{km} / \mathrm{s}$ and $\mathrm{N} 45 \mathrm{~W}$, respectively.

\section{PHASE IDENTIFICATION}

A semblance analysis of the array data shows the existence of any coherent phases and provides an estimation of the azimuth and incident angle of the wave propagation of each phase if the velocity was provided. Figure 3 shows the semblance panel of the transfer functions after P-wave arrival at $10 \mathrm{sec}$ onds. Some coherent P-wave later phases are present around 11, 12.5, 13 and 14 seconds. The panel also indicates that the later phases has smaller incident angles than that of the first P-wave arrival.

The expected travel times for each phases were estimated using the structural model compiled from the result of past studies ${ }^{8}$. Figure 5 shows the synthetic waveforms from the source at Toki where the ACROSS is located. At the array location, the reflected wave from the lower crust, the Moho discontinuity and the top of Philippine Sea Plate were estimated to arrive at 11, 13 and 14 seconds, respectively. This modeling result is consistent with a hypothesis that the coherent later-phases extracted from the semblance panel correspond to the waves propagated through the deeper crust and the waves reflected from the pate boundary.

\section{TIME EVOLUTION IN TRAVELTIME}

As shown in Figure 6, NIED reported several episodic activities of DLFTs beneath the eastern Aichi Prefecture in 2005. Among them, a strong activity at the end of July was associated with the shortterm slow slip event ${ }^{9)}$.

Temporal variations in the traveltime of the reflected phases were examined using continuous $\mathrm{Hi}-$

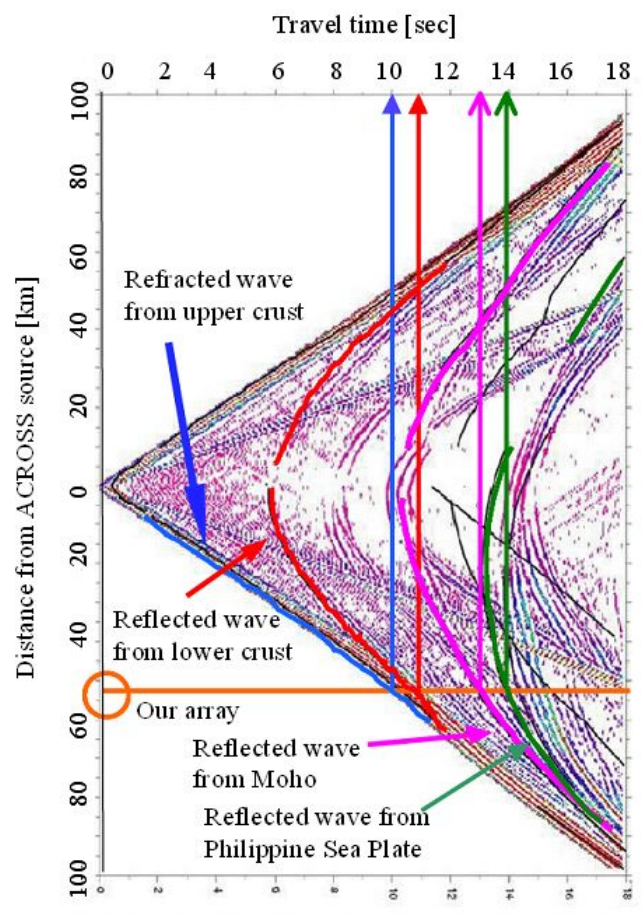

Figure 5. Synthetic waveforms from ACROSS source at $\mathrm{Toki}^{8}{ }^{8}$. The arrivals of major phases are estimated.

net data observed at the N.HOUH station. The data were stacked for three months and the windows was shifted to one month starting Jan. 2005. The phases at (a) 10.1, (b) 11.8, (c) 13.2 and (d) 13.9 seconds were extracted using a window of 0.3 seconds and cross-correlated to the corresponding phases in the reference transfer function (Term 1). Each phase are thought to correspond to the refraction from the upper crust (the first $P$ arrival), the reflected wave from the lower crust, the Moho discontinuity and the top of Philippine Sea Plate, respectively.

Figure 7 shows the temporal variation in the traveltime of the phases at (a) 10.1, (b) 11.8, (c) 13.2 and (d) 13.9 seconds. Traveltime variation of the first $P$ phase and the later phases showed temporal changes of about $1 \mathrm{~ms}$ and $4 \mathrm{~ms}$ at the maximum, respectively during the observation period.

The fact that the traveltime variation in later phases were larger than that of the first $P$ phase indicates that the cause of the traveltime delay locates beneath the upper crust. The delay of later phases increased when the DLFTs were active and recovered to the original level when the DLFTs became inactive. The temporal changes of these later phases show correlation with the episodic activity of the DLFTs in 2005.

However, the result indicates that the cause of the traveltime variation located in the crust. It is inconsistent with the recent hypothesis that tremors occur as shear faulting on the plate interface as well as slow 


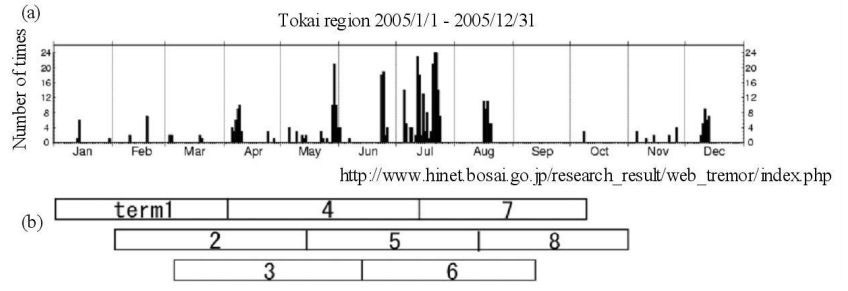

Figure 6. Activity of DLFTs in the Tokai region in 2005 reported by NIED. DLFTs were active in May, June and July. The 3-months analysis term to investigate the temporal variation are also shown.

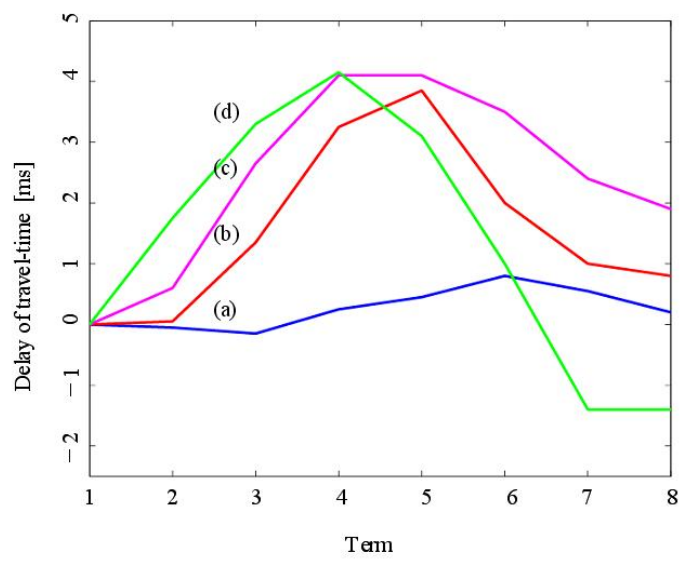

Figure 7. Time evolution of the first arrival and the reflected waves in the transfer function observed at the N.HOUH station.

$\operatorname{slip}^{10)}$.

\section{CONCLUSIONS}

An observation using the ACROSS source was conducted in the Tokai district in 2005 as a feasibility experiment of Tokai monitoring plan. The reflected phases were detected from the seismometer array data using semblance analysis and were verified by wavefield modeling. The temporal changes of these reflected phases seemed to synchronize with the activity of DLFTs under the region during the observation period.

ACKNOWLEDGMENT We are grateful to the following people for their efforts in setting and maintaining the field observation; K. Tadokoro, R. Miyajima, A. Saiga, N. Suto, M. Kashiwagi, N. Fujii (Nagoya University), M. Satomura, N. Kimura, A. Kumamoto, W.-P. Huang (Shizuoka University), T. Kunitomo, K. Tsuruga, Y. Hasada, T. Nakajima, H. Nagao (Tono Geoscience Center, JNC). We are grateful to M. Kumazawa and J. Kasahara for their enthusiastic effort on ACROSS project management, to T. Kunitomo for maintaining the ACROSS source in Toki and to Y. Yoshida (Japan Meteorological Agency) for providing the Hi-net dataset. We are grateful to Hourai Branch of Aichi Prefectural Forest Park Office, Aichi Prefectural ShinshiroShitara Construction Of- fice and Shitara Town for their cooperation in the field observation and the people in RSVD, Nagoya University for their discussion and suggestions.

\section{REFERENCE}

1) Obara, K., Nonvolcanic deep tremor associated with subduction in southwest Japan, Science, 296 , 16791681, 2002.

2) Kasahara, J., Tsuruga, K., Hasada, Y., Yamaoka, K., Fujii, N., Yoshida, Y., Kunitomo, T., and Kumazawa, M., A proposal of imaging of the plate boundary using the active monitoring method, Proc. 1st Intern. Workshop on Active Monitoring in the Solid Earth Geophysics (IWAM04), S2-03, 2004.

3) Kasahara, J., Tsuruga, K., Hasada, Y., Yamaoka, K., Kunitomo, T., Watanabe, T., Fujii, N., Yoshida, Y., and Kumazawa, M., A plan of continuous monitoring of seismic signature at the top of the subducting Philippine Sea plate using the ACROSS active monitoring method, Eos Trans. AGU, 85, Fall Meet. Suppl., Abstract S31C-07, 2004.

4) Yamaoka, K., Kunitomo, T., Miyakawa, K., Kobayashi K. and Kumazawa, M., A trial for monitoring temporal variation of seismic velocity with ACROSS system, The Island Arc, 10, 336-347, 2001.

5) Yamaoka, K., Ikuta, R., Miyakawa, K., Kunitomo, T. and Kumazawa, M., A precise method for monitoring the temporal variation of wave propagation, In Seismogenic Process Monitoring: Experiment and Mining Seismology, Balkema Publisher, 379-397, 2002.

6) Ikuta, R., Yamaoka, K. Miyakawa, K., Kunitomo, T. and Kumazawa, M., Continuous monitoring of propagation velocity of seismic wave using ACROSS, Geophys. Res. Lett., 29, 10.1029/2001GL013974, 2002.

7) Watanabe, T., Ikuta, R., Yamaoka, K., Soma, T. and Fujii, N., Continuous active seismic observation using ACROSS source and seismometer array - Toward active monitoring of Tokai seismogenic area-, Proc. 8th SEGJ Intern. Sympo., 369-372, 2006.

8) Tsuruga, K., Kasahara, J., Kunitomo, T., Hasada, Y., Ikuta, R., Watanabe, T., Yamaoka, K., Fujii, N., Kumazawa, M., Nagao, H., Nakajima, T., Saiga, A. and Satomura, M., Preliminary study for active monitoring of the plate boundary using ACROSS : Synthetic and observed seismic records, Eos Trans, AGU, 86, Fall Meet. Suppl., Abstract NG33B-0175, 2005.

9) Hirose, H. and Obara, K., Short-term slow slip and correlated tremor episodes in the Tokai region, central Japan, Geophys. Res. Lett., 33, 10.1029/2006GL026579, 2006.

10) Shelly, D. R., Beroza, G. C. and Ide, S., Non-volcanic tremor and low-frequency earthquake swarms, $\mathrm{Na}$ ture, 446, 7133, 305-307, 2007. 